\title{
IN VITRO ENDOTHELIALIZATION OF BIOPROSTHETIC HEART VALVES PROVIDES A CELL MONOLAYER WITH PROLIFERATIVE CAPACITIES AND RESISTANCE TO PULSATILE FLOW
}

Katarina Jansson, BSc ${ }^{\mathrm{a}}$

Lars Bengtsson, $\mathrm{MD}, \mathrm{PhD}^{\mathrm{b}}$

Jesper Swedenborg, $\mathrm{MD}, \mathrm{PhD}^{\mathrm{a}}$

Anders Haegerstrand, $\mathrm{MD}, \mathrm{PhD}^{\mathrm{c}}$
Objectives: Degeneration of bioprosthetic heart valves has been suggested to be at least partly an immunogenic reaction toward the xenogeneic tissue. An autologous endothelial lining has been proposed to overcome this problem. We examined in vitro endothelialization of such tissue and retention of endothelial cells after exposure to flow resembling the in vivo situation.

Methods: Cultured human saphenous vein endothelial cells were used to in vitro endothelialize photo-oxidized bioprosthetic heart valves. The endothelialized valves were mounted in a specially designed flow device, creating a pulsatile flow through the valve. Maintenance of a confluent cell layer and deposition of basement membrane markers were determined with immunohistochemical labeling.

Results: Labeling of the main components of the basement membrane, laminin and collagen type IV, was verified within 6 hours after in vitro endothelialization. Under static conditions, 4-mm wide denudations were completely re-endothelialized in 4 days, which was similar to the growth rate on gelatin-coated cell culture plastic, which served as a control material. After exposure of endothelialized valves to pulsatile flows for 24 hours ( 80 beats/min, $3.4 \mathrm{~L} / \mathrm{min}$ ), there were minimal cell losses from the bioprostheses. The cell layer adapted to the pulsatile flow, as verified by rearrangement of morphology and intracellular stress fibers.

Conclusions: This study shows the feasibility of in vitro endothelialization of photo-oxidized bioprosthetic heart valves. The cells are able to withstand a pulsatile flow in vitro, to develop basement membrane-like structures, and to re-endothelialize denuded areas. This technology may be used to enhance the performance of bioprosthetic heart valve prostheses. ( $\mathrm{J}$ Thorac Cardiovasc Surg 2001;121:108-15)
From Karolinska Institute, Department of Surgical Sciences, Karolinska Hospital, ${ }^{a}$ Stockholm, Sweden; Hjertecenter, ${ }^{\mathrm{b}}$ Varde, Esbjerg, Denmark; and Neuronova AB, ${ }^{\mathrm{c}}$ Stockholm, Sweden.

This work was supported by grants from the Swedish Heart and Lung Foundation, the Swedish Medical Research Council (project No. 09100, 07126), Lars Hiertta Foundation, Lisa and Johan Grönbergs Foundation. The research on this topic was also supported by an unrestricted grant from TERUMO EUROPE N.V., dedicated to well-being.

Received for publication May 25, 2000; revisions requested June 22, 2000; revisions received July 11, 2000; accepted for publication July 18, 2000.

Address for reprints: Katarina Jansson, BSc, Karolinska Institute, Department of Surgical Sciences, Research Center M3:01, Vascular Biology, Karolinska Hospital, S-171 76 Stockholm, Sweden (E-mail: katarina.jansson@kirurgi.ki.se).

Copyright (C) 2001 by The American Association for Thoracic Surgery

0022-5223/2001 $\$ 35.00+0 \quad \mathbf{1 2 / 1 / 1 1 0 2 5 1}$

doi:10.1067/mtc.2001.110251
Bioprosthetic devices (eg, heart valves and vascular $B_{\text {prostheses) are mostly fixed with glutaraldehyde, but }}$ this treatment is believed to be partly responsible for the lack of surface re-endothelialization as a result of toxic effects $^{1}$ and hence subsequent tissue calcification. In human subjects there is little spontaneous growth of endothelial cells (ECs) into implanted xenogeneic heart valves. Nevertheless, partial in vivo re-endothelialization of bioprosthetic valves has been reported. ${ }^{2-4}$ Preoperatively in vitro endothelializing bioprostheses with viable autologous ECs may delay or even eliminate degenerative effects, such as tissue calcification or xenogeneic immunoreactivity. Techniques have been applied to create cell linings on biologic heart valve prostheses. ${ }^{5,6}$ Glutaraldehyde preservation has, however, been shown to be incompatible with in vitro endothelializa- 
tion of bioprosthetic materials. Yet several investigators have reported enhanced cell viability by using alternative fixation procedures or detoxifying agents. ${ }^{5,7-9}$

ECs in vivo are subject to a constant pulsatile flow, and it has been shown that endothelialized vascular synthetic grafts show a better cell retention after shear stress preconditioning. ${ }^{10}$ Exposing endothelialized bioprosthetic heart valves to pulsatile stresses in vitro may therefore promote retention of seeded cells and thereby possibly optimize the EC function after implantation.

In this study we developed a flow unit in which endothelialized heart valves can be preconditioned to a pulsatile flow. When connected to this device, the valve opens and closes in a manner similar to that seen in the vivo situation. Throughout the study, we have used bovine pericardial tissue and intact heart valves preserved by dye-mediated photo-oxidation, as described by Moore and associates, ${ }^{11}$ because this material has been shown to be compatible with cultured ECs. ${ }^{8} \mathrm{We}$ used experimental conditions to establish the retention of human saphenous vein endothelial cells (HSVECs) on in vitro endothelialized bioprosthetic heart valves after exposure to the pulsatile flow system. In addition, we studied re-endothelialization of denudations within a monolayer and the deposition of basement membrane components.

\section{Materials and methods}

Cell culture. As approved by the ethical committee at the Karolinska Hospital, Stockholm, Sweden, residual segments of the great saphenous vein were collected from patients undergoing coronary bypass surgery. ECs were isolated by rinsing veins with minimal essential medium (MEM; Gibco, Life Technologies Ltd, Scotland, United Kingdom) and filled with $0.1 \%$ collagenase (Worthington, Freehold, NJ) and $0.16 \%$ dispase (Boehringer Mannheim $\mathrm{GmbH}$, Mannheim, Germany) in MEM for 20 minutes at $37^{\circ} \mathrm{C}$ in an $8 \%$ carbon dioxide-humidified atmosphere. Cells were collected and thereafter cultured in MEM containing $40 \%$ heat-inactivated pooled human serum (HS; $56^{\circ} \mathrm{C}$ for 30 minutes), $1 \mathrm{nmol} / \mathrm{L}$ choleratoxin (Sigma Chemical Company, St Louis, Mo), 33 $\mu \mathrm{mol} / \mathrm{L}$ isobutylmethylxantine (Sigma), and antibiotics (penicillin, $50 \mathrm{U} / \mathrm{mL}$, and streptomycin, $50 \mu \mathrm{g} / \mathrm{mL}$; Gibco). ${ }^{12}$ The HSVECs were seeded in gelatin-coated $(0.2 \%$ in phosphatebuffered saline solution [PBS] for 30 minutes at $4{ }^{\circ} \mathrm{C}$, Sigma) cell culture vessels (Costar, Cambridge, Mass) and passaged (1:3) with trypsin $(0.05 \%)$ and ethylenediamine tetraacetic acid $(0.01 \%)$. The HSVECs were characterized with monoclonal anti-human von Willebrand factor-related antigen (1:100; Dako, A/S, Glostrup, Denmark). HSVECs between passages 4 and 7 were used in the experiments.

Bioprosthetic material. Bovine pericardial tissue preserved with dye-mediated photo-oxidation was used through-

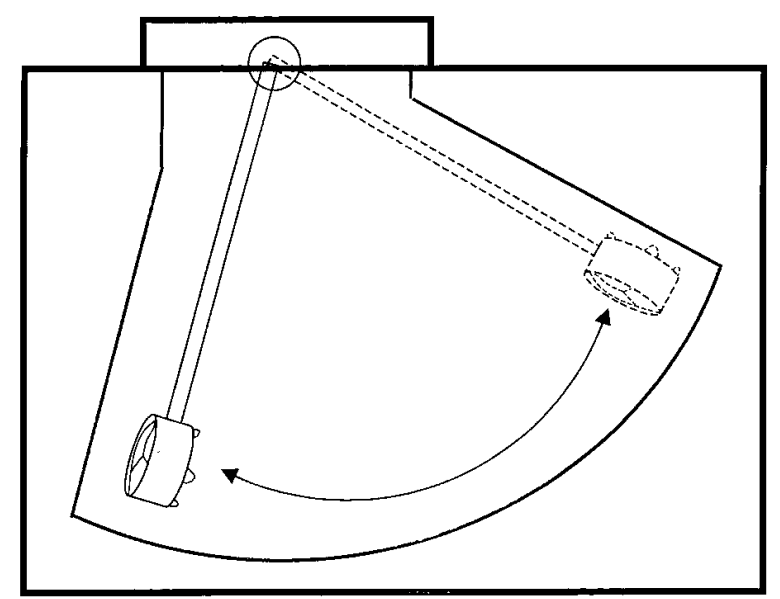

Fig 1. Schematic outline of the pulsatile flow device. The endothelialized heart valve is mounted to an arm that is subject to a pendular movement by attachment to a motor. When the arm is set in motion, a controller may adjust the frequency of the pulsatile flow. The heart valve prosthesis will open or close, depending on the back-and-forth movement. The length of the arm from the axis to the center of the valve is $100 \mathrm{~mm}$. The total length of the pendular movement of the valve is $873 \mathrm{~mm}$.

out the study (kindly provided by Sulzer Carbomedics, Inc, Austin, Tex). For the flow studies, intact PhotoFix $\alpha$-bioprostheses (Sulzer Carbomedics, Inc, Austin, Tex) (23 or $25 \mathrm{~mm}$ in diameter) were used. The bioprosthetic material was stored in alcohol and rehydrated in PBS. Before seeding, the valves and tissues were preincubated in MEM with $30 \% \mathrm{HS}$ for 2 to 4 hours.

Endothelialization of bioprosthetic tissue. The bovine pericardial tissue was cut into round patches corresponding to the size of a well in 24-well plates ( 1 patch per well; Costar). Two days before experiments, the bioprosthetic tissue was endothelialized with cultured HSVECs at a density of $1.5 \times$ $10^{5}$ cells $/ \mathrm{cm}^{2}$ in MEM containing 30\% HS and antibiotics.

Endothelialization of bioprosthetic heart valves. The intact photo-oxidized heart valves were in vitro endothelialized in a stepwise fashion, essentially as described by Bengtsson and associates. ${ }^{6}$ We used supraphysiologic cell densities for endothelialization to achieve an immediate and confluent cell layer. The bioprosthetic valve was mounted in a rotating device so that each cusp could be placed in an upright position. For endothelialization of the inflow aspect of the valve, a cell suspension $\left(4 \times 10^{6}\right.$ HSVECs in $8 \mathrm{~mL}$ of MEM with $30 \% \mathrm{HS}$ and antibiotics, $5 \times 10^{5} \mathrm{HSVECs} / \mathrm{cm}^{2}$ ) was allowed to adhere for 15 minutes per cusp. For endothelialization of the outflow surfaces, the valve prosthesis was turned, and thereafter another $8 \mathrm{~mL}$ of cell suspension $(4 \times$ $10^{6}$ HSVECs) was infused into the seeding device (15 minutes per cusp). In addition, the commissures were placed in an upright position for 10 minutes each. Thereafter, the in 


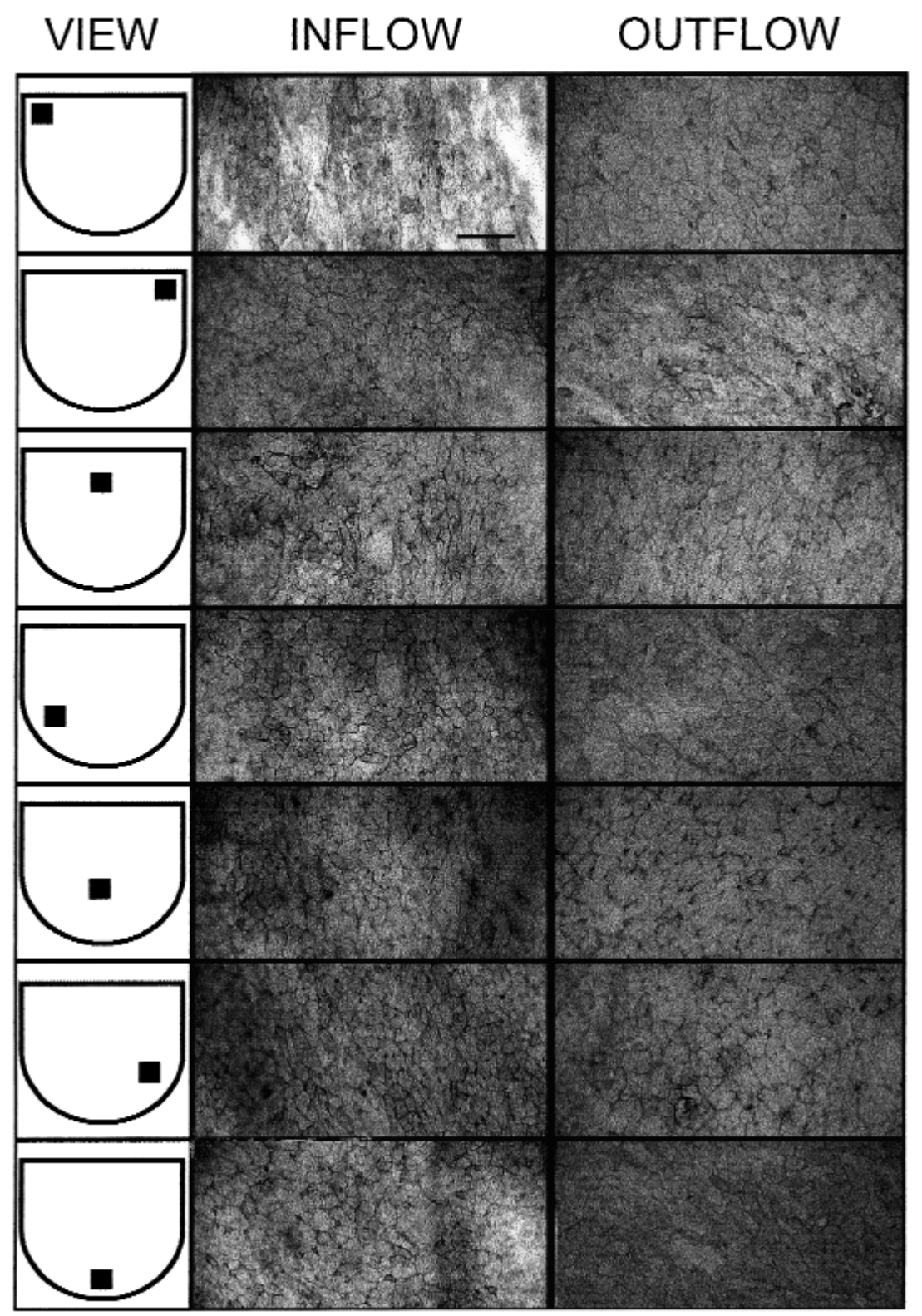

Fig 2. Verification of an intact HSVEC monolayer on the heart valve prosthesis with immunohistochemical labeling of CD31. A representative endothelialized cusp is shown after exposure to a pulsatile flow for 24 hours (80 beats $/ \mathrm{min}, 3.4 \mathrm{~L} / \mathrm{min}$ ). The left panel shows schematic cusps, with filled squares indicating the position of illustrations on the inflow and outflow side of the same cusp. White areas on the inflow illustrations are areas out of focus because of the rough surface $($ bar $=50 \mu \mathrm{m})$.

vitro endothelialized heart valve was kept under static conditions for an additional 2 days before exposure to pulsatile flow. The experiments were repeated 4 times with different HSVEC donators obtaining similar results.

In vitro pulsatile flow of heart valves. The intact in vitro endothelialized heart valve prosthesis was connected to a specially designed flow device connected to a controller that sets an adjustable frequency and speed of a motor, hence adjust- ing the volume of medium (MEM containing 30\% HS) flowing through the valve. The resulting flow opens and closes the heart valve by means of a pendular movement (Fig 1). Endothelialized heart valve prostheses were exposed to flow for 24 hours $(3.4 \mathrm{~L} / \mathrm{min}, 80$ beats $/ \mathrm{min}$ ) or maintained in static culture as controls. Throughout the studies, the flow device was placed in an incubator with $95 \%$ humidity and $8 \%$ carbon dioxide. 

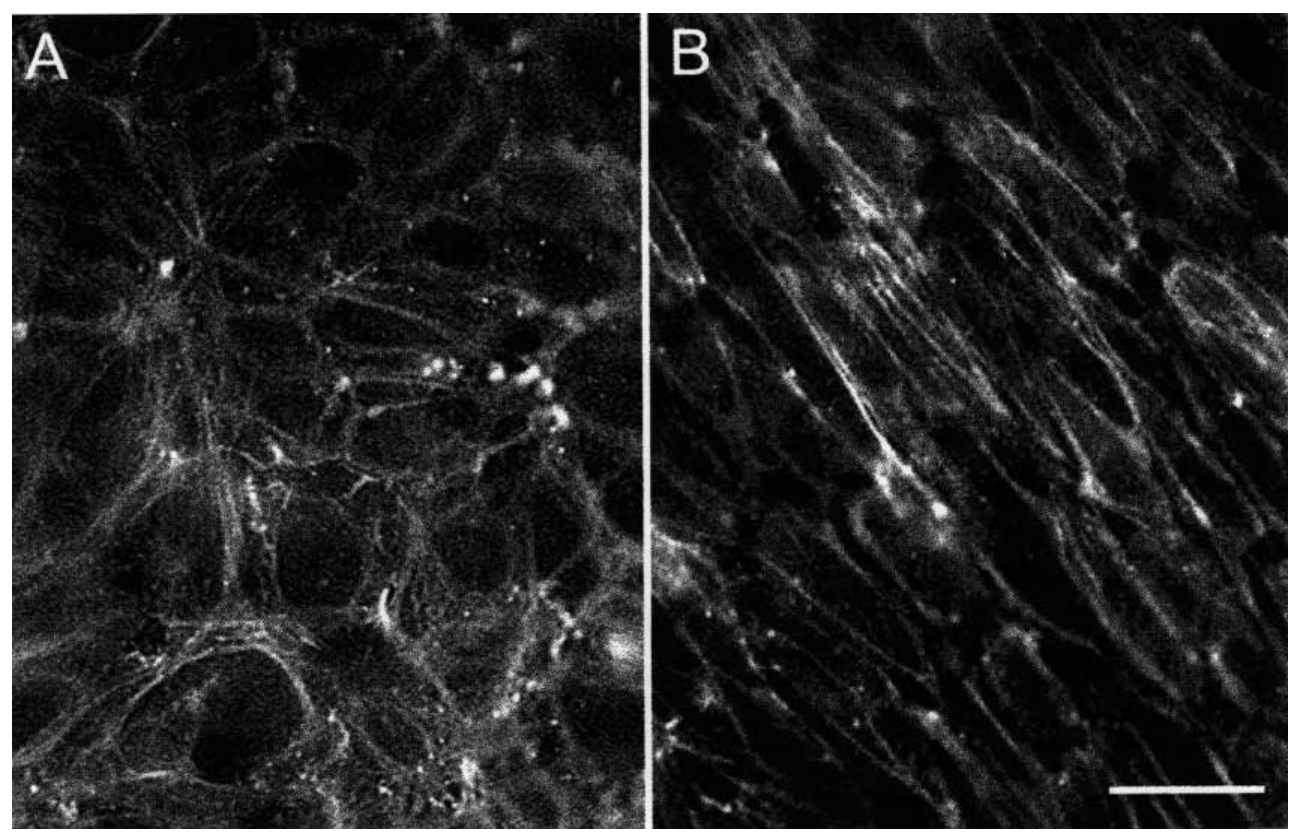

Fig 3. Immunohistochemical labeling of the actin distribution in HSVECs on endothelialized heart valve leaflets incubated under static condition (A) or exposed to a pulsatile flow for 24 hours (B). The static control showed ECs with a cobblestone morphology, and the dense peripheral bands were more prominent compared with the flowexposed HSVECs $($ bar $=50 \mu \mathrm{m})$.

Indirect immunohistochemical labeling. Indirect immunohistochemical labeling was used to verify the EC monolayer and to study the basement membrane deposition and location of intracellular stress fibers in HSVECs seeded on bioprosthetic tissue. The monoclonal anti-human antibodies used were CD31 (1:100, Dako), laminin (1:100, Boehringer-Mannheim), collagen type IV (1:100, Dako), and actin (1:100, Sigma). For detection, biotinylated antibodies (1:200; Vector Laboratories, Inc, Burlingame, Calif) and streptavidin-conjugated Cy-3 (1:200; Jackson Immuno Research Laboratories, Inc, West Grove, Pa) or the ABC-kit (Vector) with subsequent AEC development (Vector) were used. All antibodies were diluted in PBS alone or in $0.3 \%$ Triton in PBS. The heart valves were fixed in $4 \%$ formaldehyde in PBS; otherwise, nonfixed materials were used. Mouse monoclonal anti-immunoglobulin $\mathrm{G}_{1}$ (1:20, Dako) or secondary antibodies only were used as negative controls.

In vitro model for endothelial repair. Two days before in vitro endothelialization of bioprosthetic tissue, HSVECs were stained with $2.5 \mu \mathrm{g} / \mathrm{mL}$ 1,1-dioctadecyl-3,3,3',3'tetramethylindocarbocyanine-perchlorate (Molecular Probes Inc, Eugene, Ore) in cell culture medium for 30 minutes. Before endothelialization, an area in the middle $(4 \times 10 \mathrm{~mm})$ was covered by a stainless steel weight to mediate a cell-free area. Two days after in vitro endothelialization, the steel weight was removed, and a 4-mm wide gap devoid of cells was thus created, representing a defect in the endothelial monolayer (regarded as day 0). HSVECs seeded on gelatincoated cell culture plastic (24-well plates, Costar) served as controls. During re-endothelialization, the HSVECs were incubated in MEM with $40 \%$ HS, choleratoxin, and isobutylmethylxantine to mediate proliferation. ${ }^{12}$ Re-endothelialization of the cell-free areas was verified on days 1 to 5 in a Nikon epifluorescence microscope (Eclipse, E-800, Yokohama, Japan). The experiment was repeated with HSVECs isolated from 5 different donors with similar results.

\section{Results}

Exposure to pulsatile flow. The in vitro endothelialized heart valve prosthesis was shown to maintain an HSVEC monolayer after exposure to a pulsatile flow for 24 hours at 80 beats/min, corresponding to 3.4 $\mathrm{L} / \mathrm{min}$ passing through the valve (Fig 2). There were essentially no cell losses after 24 hours. Only denudations a few cells wide could be seen in 1 to 3 areas per cusp. The inflow surfaces of the cusps were rougher than the smooth outflow surfaces, but the endothelial lining could be followed on top of the fibrils. The HSVECs showed some alignment, possibly because of the pulsatile flow, and there were also minor differences in the distribution of HSVECs in the central part of the cusps compared with the peripheral parts.

Intracellular stress fibers. The distribution of actin in HSVECs changed after exposure of the endothelial- 

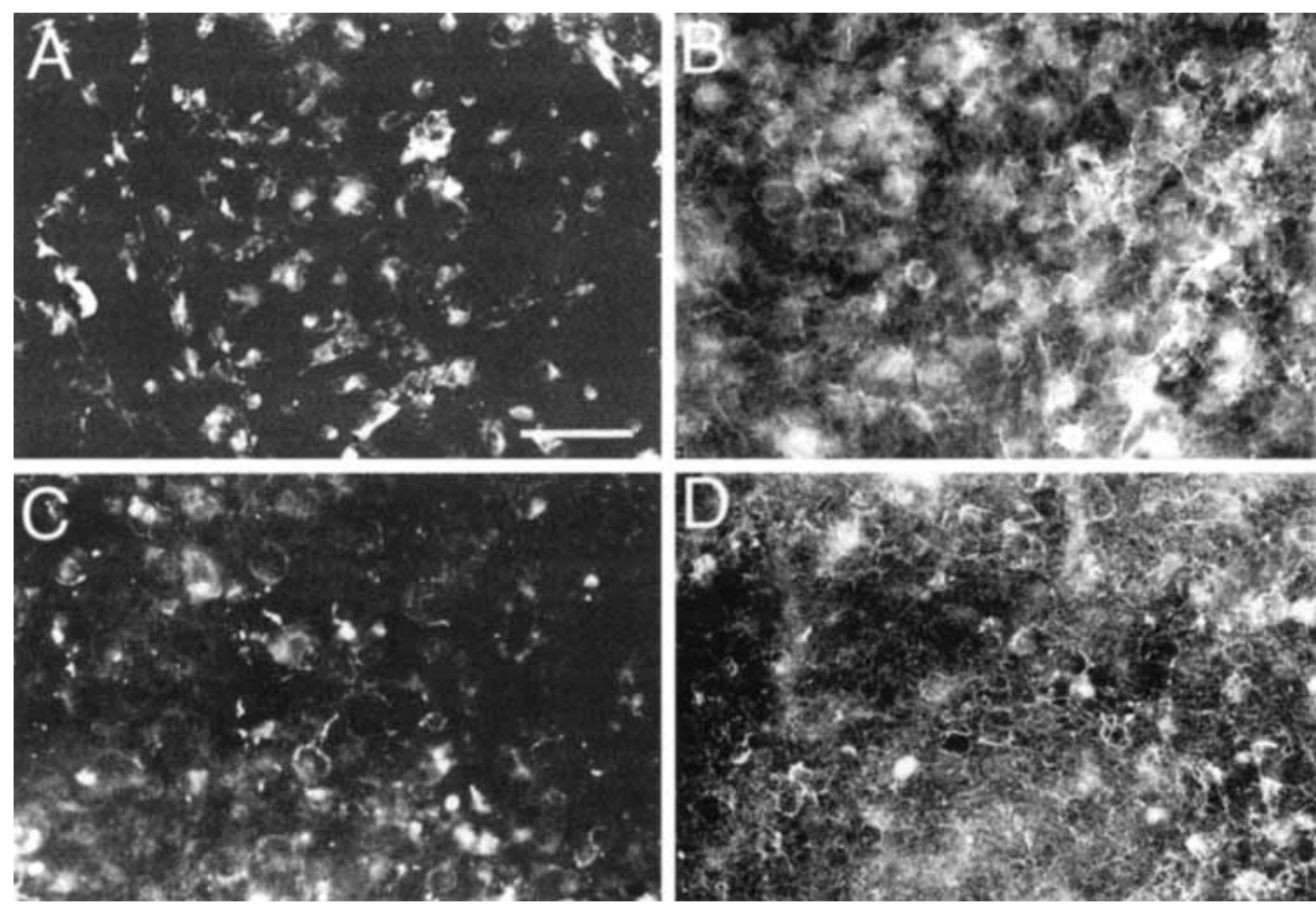

Fig 4. Basement membrane deposition by HSVECs seeded on bioprosthetic tissue, as verified with immunofluorescent labeling of laminin (A, B) and collagen type IV (C, D). Six hours after confluent endothelialization, HSVECs showed weak staining, mostly intracellular, of both laminin (A) and collagen type IV (C). After 24 hours, there was subendothelial labeling of both antigens (B and $\mathbf{D})$, indicating a reconstituted basement membrane $($ bar $=100 \mu \mathrm{m})$.

ized heart valves to the pulsatile flow ( 80 beats/min for 24 hours). The static control showed cobblestoneshaped HSVECs, with labeling of actin fibers in dense peripheral bands (Fig 3,A). The HSVECs exposed to pulsatile flow were elongated and showed less actin labeling (ie, a less-pronounced dense peripheral band), but staining was still mainly associated to the cell periphery (Fig 3, B), indicating reorganization in association with a change in cell morphology.

Basement membrane deposition. Six hours after confluent seeding of HSVECs on the bioprosthetic tissue, there was mostly weak intracellular staining of both laminin and collagen type IV (Fig 4, $A$ and $C$ ). After 24 hours in culture, laminin and collagen type IV were deposited into the extracellular matrix, as verified by subendothelial labeling of thin fibrils (Fig 4, $B$ and $D$ ). There was no apparent change in the staining pattern of collagen type IV after exposure to pulsatile flow (data not shown).

Endothelial repair. At day 0, the endothelial monolayers were facing a 4-mm wide gap devoid of cells on the bioprosthetic tissue (Fig 5, A). There was a rapid migration-proliferation of HSVECs into the cell-free area, and after 2 days, approximately two thirds of the cell-free area was re-endothelialized (Fig 5, B, day 2). Within 4 days, the re-endothelialization process was completed, resulting in a confluent cell layer (Fig 5, C). The growth rate was similar to that of HSVECs seeded on gelatin-coated cell culture plastic (data not shown). CD31 labeling confirmed the HSVECs, and individual cells could be seen during re-endothelialization (Fig 5, $D$, day 3 ).

\section{Discussion}

In this study we report the feasibility of confluent in vitro endothelialization of bioprosthetic heart valves by using cultured adult HSVECs, and we demonstrate maintenance of the EC monolayer after exposure to an in vitro pulsatile flow for 24 hours.

During the normal cyclic performance of the aortic valve, its leaflets are subjected to continuous bending and shearing stresses, as well as various pressures. The pulsatile flow unit was developed to simulate in vivo conditions by mediating opening and closing of the 

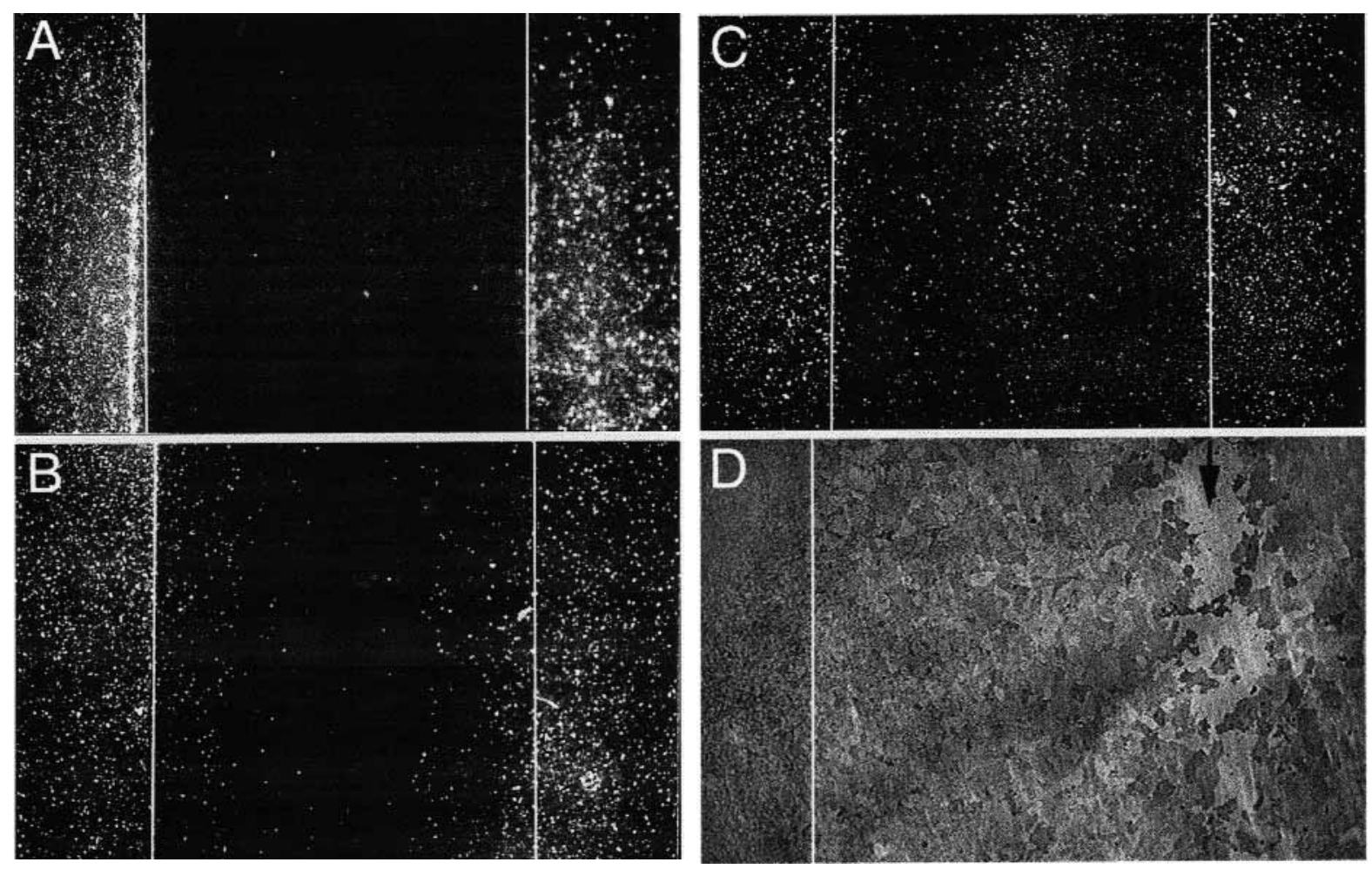

Fig 5. Re-endothelialization by HSVECs on bioprosthetic tissue as verified with 1,1-dioctadecyl-3,3,3',3'-tetramethylindocarbocyanine-perchlorate labeling (A-C). At the day of exposure (A, day 0), there was a 4-mm wide gap devoid of cells in the endothelial monolayer. After exposure of HSVECs to the cell-free area, migration-proliferation was initiated (B, day 2), and re-endothelialization was completed within 4 days (C). Distance between lines (A-C) is $4 \mathrm{~mm}$. D, A higher magnification shows CD31 labeled HSVECs at day 3 of re-endothelialization. The arrow represents the center of the denuded area, and the distance between the line and arrow is $2 \mathrm{~mm}$.

mounted heart valve in a pendular movement. In this study we only showed the usefulness of the flow device as a tool for studying cell retention on endothelialized heart leaflets and did not evaluate shear stress or pressure at the cuspal areas. The measurement of flow rates reflects the volume of media passing through the valve per time unit. In preliminary studies we used various flow rates, ranging from $1 \mathrm{~L} / \mathrm{min}$ ( 24 hours) to 6.5 L/min (1 hour), without having any major cell losses. The adaptation of HSVECs to the pulsatile flow was indicated by the change in morphology and verified by actin reorganization. The alignment of ECs was not uniform throughout the endothelialized cusps, independent of inflow or outflow aspect. This suggests rather complex flow patterns within the valve, possibly by both longitudinal and cyclic stresses. ${ }^{13}$ Orientation of cultured ECs during exposure to stress has been reported to take up to 24 hours, ${ }^{14}$ which is similar to that found in our model. We also noted some differences in cell orientation between different cusps. This may be explained by alignment of ECs with the arrangement of collagen fibers in the cuspal tissue. ${ }^{15}$

In our experiments the endothelialized heart valves were kept in static culture for 2 days before exposure to shear stress. This time has been shown to mediate deposition of basement membrane, ${ }^{16}$ as well as a reduction in cell-adhesion molecule expression ${ }^{17}$ by HSVECs seeded on cardiovascular materials. Reports suggest the outcome of cell retention on vascular grafts after exposure to flow may be influenced by the in vitro incubation time and precoating matrix. ${ }^{18,19}$ Preconditioning of EC-lined vascular grafts to shear stress may also improve cell retention. ${ }^{10,20}$ Initially, a loss of cells has been reported, but after a continued exposure, cell detachment is gradually decreased ${ }^{21}$ and possibly counteracted by cell proliferation. ${ }^{22}$ We did not extend our in vitro flow studies beyond 24 hours, but during that time, we did not see any major cell detachment. Therefore, we believe the intact monolayer seen after 24 hours 
results from the endothelialization with HSVECs, but we cannot exclude that proliferating cells may have healed small denudations.

In the normal endothelium no denudations are seen, even those only a few cells wide. High shear stresses or mechanical disruption can easily cause endothelial injury on endothelialized grafts. The maintenance of differentiated functions by ECs after in vitro culture, such as cell-matrix interactions, may well influence the adhesive and regenerative properties of HSVECs used for endothelialization of bioprosthetic heart valves. Aortic EC adhesion and migration has been shown to preferentially be promoted by collagen type IV compared with laminin, ${ }^{23}$ whereas others have shown laminin to enhance EC adhesion in a shear stress environment. ${ }^{24}$ The rapid deposition of laminin and collagen type IV by HSVECs on photo-oxidized tissue may thus be beneficial for the EC retention on flow-exposed endothelialized heart valves, as well as having effects on the re-endothelialization process. It has been shown that in vitro re-endothelialization is a combination of proliferation and migration and also dependent on the underlying matrix ${ }^{16,25}$ and that extracellular matrix produced by canine ECs on polytetrafluoroethylene vascular grafts promotes proliferation and shear stress resistance of the cells. ${ }^{26}$ The adhesive and regenerative capacities showed by HSVECs may be useful after implantation of in vitro endothelialized grafts because regrowth of an endothelial monolayer over denuded areas as a result of, for example, minor handling trauma, probably develops from an intact endothelium, as in our re-endothelialization model.

In vitro endothelialization was performed on photooxidized bioprosthetic tissue, which does not require any detoxification except eluting ethanol, which serves as a storage solution. ${ }^{11}$ This fixation method has been reported to provide an EC-compatible matrix ${ }^{8}$ that is less calcified than ordinary glutaraldehyde-fixed bioprosthetic material after implantation. ${ }^{27}$ Because of the toxic actions of aldehydes, alternative fixation methods or detoxification is needed for studies of in vitro endothelialization. Detoxifying agents render the bioprosthetic tissue more cell compatible as regards proliferation, ${ }^{28}$ but the attachment of cells is still limited ${ }^{29}$ and contains nonviable cells. ${ }^{6}$ Implantation of a neutralized and endothelialized glutaraldehyde-fixed xenograft valve in the nonhuman primate showed uncoated areas despite the use of fibronectin pretreatment. ${ }^{30}$ Therefore, to allow complete and durable endothelialization, novel nontoxic materials, such as photo-oxidized pericardium, are desirable.

In conclusion, the data presented in this study show that photo-oxidized heart valves can be in vitro endothelialized with adult cultured HSVECs to complete confluency. The HSVECs deposit a basement membrane structure and show regenerative properties. Without the use of any detoxifying agents or any pretreatment of the valves with growth factors or adhesive proteins (eg, fibronectin or collagen type I), the cells were able to remain attached to the photo-oxidized biomaterial after exposure to a flow resembling the in vivo situation. In this specially designed flow device, in vitro endothelialized bioprostheses may be tested or preconditioned to different pulsatile flows before implantation.

\section{REFERENCES}

1. Eybl E, Griesmacher A, Grimm M, Wolner E. Toxic effects of aldehydes released from fixed pericardium on bovine aortic endothelial cells. J Biomed Mater Res 1989;23:1355-65.

2. Ishihara T, Ferrans VJ, Jones M, Boyce SW, Roberts WC. Occurrence and significance of endothelial cells in implanted porcine bioprosthetic valves. Am J Cardiol 1981;48:443-54.

3. Zavazava N, Simon A, Sievers HH, Bernhard A, MüllerRochholz W. Porcine valves are reendothelialized by human recipient endothelium in vivo. $\mathrm{J}$ Thorac Cardiovase Surg 1995;109:702-6.

4. Simon A, Wilhelmi M, Steinhoff G, Harringer W, Brucke P, Haverich A. Cardiac valve endothelial cells: relevance in the long-term function of biologic valve prostheses. J Thorac Cardiovasc Surg 1998;116:609-16.

5. Eberl T, Siedler S, Schumacher B, Zilla P, Schlaudraff K, Fasol R. Experimental in vitro endothelialization of cardiac valve leaflets. Ann Thorac Surg 1992;53:487-92.

6. Bengtsson L, Radegran K, Haegerstrand A. In vitro endothelialization of commercially available heart valve bioprostheses with cultured adult human cells. Eur J Cardiothorac Surg 1993; 7:393-8.

7. Fischlein T, Lehner G, Lante W, Fittkau M, Murphy JG, Weinhold C, et al. Endothelialization of cardiac valve bioprostheses. Int J Artif Organs 1994;17:345-52.

8. Bengtsson LA, Phillips R, Haegerstrand AN. In vitro endothelialization of photooxidatively stabilized xenogeneic pericardium. Ann Thorac Surg 1995;60:S365-8.

9. Zilla P, Fullard L, Trescony P, Meinhart J, Bezuidenhout D, Gorlitzer M, et al. Glutaraldehyde detoxification of aortic wall tissue: a promising perspective for emerging bioprosthetic valve concepts. J Heart Valve Dis 1997;6:510-20.

10. Ott MJ, Ballermann BJ. Shear stress-conditioned, endothelial cell-seeded vascular grafts: improved cell adherence in response to in vitro shear stress. Surgery 1995;117:334-9.

11. Moore MA, Bohachevsky IK, Cheung DT, Boyan BD, Chen WM, Bickers RR, et al. Stabilization of pericardial tissue by dyemediated photooxidation. J Biomed Mater Res 1994;28:611-9.

12. Haegerstrand A, Gillis C, Bengtsson L. Serial cultivation of adult human endothelium from the great saphenous vein. J Vasc Surg 1992;16:280-5.

13. Iba T, Sumpio BE. Morphological response of human endothelial cells subjected to cyclic strain in vitro. Microvasc Res 1991;42:245-54.

14. Galbraith CG, Skalak R, Chien S. Shear stress induces spatial 
reorganization of the endothelial cell cytoskeleton. Cell Motil Cytoskeleton 1998;40:317-30.

15. Deck JD. Endothelial cell orientation on aortic valve leaflets. Cardiovasc Res 1986;20:760-7.

16. Jansson K, Bengtsson L, Haegerstrand A. Time-course for in vitro development of basement membrane, gap junctions, and repair by adult endothelial cells seeded on precoated ePTFE. Eur J Vasc Endovasc Surg 1998;16:334-41.

17. Gillis C, Bengtsson L, Haegerstrand A. Reduction of monocyte adhesion to xenogenic tissue by endothelialization: an adhesion molecule and time-dependent mechanism. J Thorac Cardiovasc Surg 1995;110:1583-9.

18. Prendiville EJ, Coleman JE, Callow AD, Gould KE, LaliberteVerdon S, Ramberg K, et al. Increased in vitro incubation time of endothelial cells on fibronectin-treated ePTFE increases cell retention in blood flow. Eur J Vasc Surg 1991;5:311-9.

19. Consigny PM, Vitali NJ. Resistance of freshly adherent endothelial cells to detachment by shear stress is matrix and time dependent. J Vasc Interv Radiol 1998;9:479-85.

20. Dardik A, Liu A, Ballermann BJ. Chronic in vitro shear stress stimulates endothelial cell retention on prosthetic vascular grafts and reduces subsequent in vivo neointimal thickness. J Vasc Surg 1999;29:157-67.

21. Zhu L, Williams WG, Bellhouse B, Pugh S, Rabinovitch M. Effective endothelialization of polyurethane surfaces: response to shear stress and platelet adhesion. ASAIO Trans 1990;36:811-6.

22. Thompson M, Budd J, Eady S, James R, Bell P. Effect on pulsatile shear stress on endothelial attachment to native vascular surfaces. Br J Surg 1994;81:1121-7.

23. Herbst TJ, McCarthy JB, Tsilibary EC, Furcht LT. Differential effects of laminin, intact type IV collagen, and specific domains of type IV collagen on endothelial cell adhesion and migration. J Cell Biol 1988;106:1365-73.

24. Schnittler HJ, Franke RP, Akbay U, Mrowietz C, Drenckhahn D. Improved in vitro rheological system for studying the effect of fluid shear stress on cultured cells. Am J Physiol 1993;265:C28998.

25. Madri JA, Pratt BM, Yannariello-Brown J. Matrix-driven cell size change modulates aortic endothelial cell proliferation and sheet migration. Am J Pathol 1988;132:18-27.

26. Schneider A, Chandra M, Lazarovici G, Vlodavsky I, Merin G, Uretzky G, et al. Naturally produced extracellular matrix is an excellent substrate for canine endothelial cell proliferation and resistance to shear stress on PTFE vascular grafts. Thromb Haemost 1997;78:1392-8.

27. Grabenwoger M, Sider J, Fitzal F, Zelenka C, Windberger U, Grimm M, et al. Impact of glutaraldehyde on calcification of pericardial bioprosthetic heart valve material. Ann Thorac Surg 1996;62:772-7.

28. Eybl E, Grimm M, Grabenwoger M, Bock P, Muller MM, Wolner E. Endothelial cell lining of bioprosthetic heart valve materials. J Thorac Cardiovasc Surg 1992;104:763-9.

29. Leukauf C, Szeles C, Salaymeh L, Grimm M, Grabenwoger M, Losert $\mathrm{U}$, et al. In vitro and in vivo endothelialization of glutaraldehyde treated bovine pericardium. J Heart Valve Dis 1993;2:230-5.

30. Lehner G, Fischlein T, Baretton G, Murphy JG, Reichart B. Endothelialized biological heart valve prostheses in the nonhuman primate model. Eur J Cardiothorac Surg 1997;11:498504 .

\section{Online-www.aats.org}

Now you can get The Journal of Thoracic and Cardiovascular Surgery online.

The Journal online brings you faster delivery time, easy searching of current and back issues, links to PubMed, AATS, WTSA, and other important sites, and more. Visit the Journal online today.

\section{Receive tables of contents by e-mail}

To receive the tables of contents by e-mail, sign up through our Web site at http://www.mosby.com/jtcvs Choose E-mail Notification

Simply type your e-mail address in the box and click the Subscribe button.

Alternatively, you may send an e-mail message to majordomo@mosby.com.

Leave the subject line blank and type the following as the body of your message: subscribe jtcvs_toc

You will receive an e-mail to confirm that you have been added to the mailing list. Note that TOC e-mails will be sent out when a new issue is posted to the Web site. 